\title{
Who Am I, Professionally Speaking?
}

\author{
John G. Halvorsen, $M D, M S$
}

I don't know about you, but I've been feeling a little uneasy recently about my professional identity as a family physician. Some may ascribe it to the existential angst of a middle-aged professional struggling through a stage in my developmental life cycle, and for a time I assumed that this concern was personal. But I've come to realize that other family physicians, even younger ones, are also worried and perhaps a bit confused about their professional identities.

This has not always been the case for me. After graduating from medical school, completing a rotating internship, practicing for 2 years in a rural community, and then finishing a family practice residency in 1976, I knew who I was professionally. I was a family physician. I believed that I could care for whole families in a comprehensive, continuous, compassionate, personalized manner, regardless of their age, ethnicity, sex, or clinical complaints. Furthermore, I was a complete physician whose practice was not limited by procedure, diagnosis, or organ system. In fact, I could provide definitive care for 85 to 90 percent of the problems that patients brought to me, including all their preventive care needs. For those remaining 10 to 15 percent I could "call in" (my grandmother's term for specialty consultation) someone to assist with care, to support the process that my patient partner and I together had initiated. I understood that I was prepared to offer society something that was unique, valued, and socially responsible.

I believed I was fulfilling the role that the Millis ${ }^{1}$ and Willard ${ }^{2}$ reports had clearly defined. These works, seminal to the formation of our discipline, emphasized the need to train physicians who could provide personalized, comprehensive, and continuing care; who could reassemble the

Submitted, revised, 7 June 1998.

From the Department of Family and Community Medicine, University of Illinois College of Medicine at Peoria. Address reprint requests to John $\mathrm{G}$. Halvorsen, MD, MS, University of Illinois College of Medicine at Peoria, One Illini Drive, Box 1649. Peoria, IL 61656. fragmenting components of the patient care system; and who could practice both scientific and humanistic medicine as a new kind of specialist in family medicine. This physician was also the type advocated by our early family medicine proponents-Geyman, ${ }^{3,4} \mathrm{McWhinney,}{ }^{5,6}$ Pisacano, $^{7}$ Brucker, ${ }^{8}$ Spitzer, ${ }^{9}$ Stephens, ${ }^{10-16}$ Sergent,,${ }^{17}$ and Carmichael. ${ }^{18-20}$

Such was my identity as a family physician, and by and large, this was how most other physicians in the community where I practiced understood me as well. Now, however, I'm worried that this identity, this uniqueness, is starting to disintegrate. My worry is stimulated by the many new names to describe my professional role. These names, I believe, represent sentinel symptoms of potentially serious and perhaps deleterious change.

When any group or organization begins to experience a change in roles and identity, new names are chosen to characterize and describe it in novel, often slightly different, ways. This renaming is now happening to family physicians. In contemporary American medicine we are increasingly defined professionally by a host of other appellations -family practitioner, generalist, primary care physician, primary care clinician, primary care provider, and most depersonalized of all, a threeletter abbreviation-PCP (and I thought that was an illicit drug).

This situation disturbs me because the process and outcomes of naming are not trivial. Names carry consequences. They define us, they classify us, they determine what other people think about us, they determine how we think about ourselves, and they indicate our role in society. They are the first point of connection between strangers ("I'm glad to meet you, Dr. Doe, and what is your specialty?"). Introductory names create an immediate basis for impressions, opinions, and associations. Names also influence the course of lives and behaviors in subtle ways that might not even be consciously recognized. (Notice how the behavior of some medical students changes as soon 
as they match with a residency-training program and thereby acquire their specialty label.) Names inspire emotional reactions, they are used to praise or deride, and they touch the core of our personal identity.

In addition to these largely unintended results, the process of naming also leads to a set of intended consequences. According to Hayakawa, ${ }^{21}$ the first major intended consequence is classification. He reminds us that "the individual object or event we are naming... has no name and belongs to no class until we put it in one." Furthermore, classification frequently does not attempt to capture universal truth, or as he terms it, "identify essences," but rather, reflects "social convenience and necessity." Different "necessities" produce different classifications, and society regards as true those classification systems that produce the results it ultimately desires. Regardless of the system that created the classification, however, once completed, it profoundly determines attitudes and conduct toward that which has been named. For this reason, it is important to guard our professional name jealously and to be vigilant in assuring we are not reclassified with new names that redefine our professional role and identity in ways which will diminish them.

Another critically important attribute associated with a name is reputation. In fact, name often implies reputation. This concept might have originated from biblical references such as Proverbs $22: 1$, in which the writer says, "A good name is rather to be chosen than great riches," or where in Ecclesiastes 7:1 it is written, "A good name is better than precious ointment." Shakespeare ${ }^{22}$ also noted the value of name as reputation when he wrote in Otbello, "But he that filches from me my good name robs me of that which not enriches him and makes me poor indeed."

My family physician name, and through it my identification with those who dedicated themselves to establish its credibility, is a great source of personal and professional pride. It is a good name, a revered name that connects me with the physician's historical role and that grounds me in long-standing tradition and professional values. Periodically I remind my specialty colleagues that the family physician's role did not begin de novo with the formation of a professional organization, a certifying body, or residency-training programs. Our professional societies and certifying bodies are important because they authenticate us to oth ers as bona fide, but our history reaches far back into the time-honored knowledge, practice, an traditions of the general medical practitioner and of those who provided comprehensive and contin- 3 uing medical care for individuals and familieso throughout history.

I feel much less enthusiastic about the news names that others now attach to me. I believe be-음 fore we willingly adopt them, we should examines them closely and carefully consider their potentia $\frac{\vec{b}}{2}$ impact on our professional role and identity asin family physicians.

Other specialty colleagues frequently refer to me as a family practitioner, a hybrid name, mixing family physician with general practitioner. This nameo recognizes our historical roots and traditions, but it does not make good literal sense. A practitioner is someone who applies knowledge rather than just possesses it. A family practitioner, then, iso someone who applies or practices knowledgeabout families. Family therapists, family socials workers, and even parents would potentially qual-ọ̄ ify as family practitioners.

In this same vein, the applied term for our specialty-family practice-is also in some sense inex-응 act. Family medicine is the recognized term that de-s scribes the body of knowledge and the skills thato constitute our medical discipline. ${ }^{3-5,23}$ Familyo physicians practice family medicine by applying its $\overrightarrow{\overrightarrow{0}}$ knowledge and skills; likewise, our graduate edu- $\frac{3}{5}$ cation programs train residents to practice familyo medicine by teaching them that knowledge ands those skills. I suspect, however, even if familys practice and family practice residency are somewhat imprecise terms, they will endure, supported $\overrightarrow{3}$ by tradition and common usage.

Another popular term used to classify our pro-윽 fession is generalist. This name connotes both fa-N vorable and unfavorable attributes. On the posi- $-\frac{D}{0}$ tive side, it serves to connect family physicians with other physicians in adult and pediatric medi-N cine who share with us many common attributes, goals, and commitments. Generalist also describeso professional activity that belongs and applies to the whole (person, family, community, health care system, etc) rather than to a limited part; it is in- $\frac{\overrightarrow{0}}{\overline{0}}$ clusive rather than exclusive, pertains to the needs $\frac{\text { ? }}{\mathrm{D}}$ of most patients, focuses on universals rather than particulars, encompasses a broad scope, diversity, and variety rather than being confined by special-o 
ization or careful limitation, and involves or affects practically the entire organism.

Despite these admirable qualities embodied in the name generalist, it also implies several less desirable traits. Those who question the value of generalism emphasize that the focus of the term is approximate rather than strictly accurate. I know of no family physicians, however, who want their professional practices characterized as only approaching the mark but never on target. Furthermore, general implies a state of belonging to the common, nondescript, undifferentiated, generic class, and is, in fact, how many integrated health care systems now view family physicians. They are often sought after because the system views them as the most basic, multipotential, interchangeable physicians in the workforce. In this role they are used to meet corporate goals for efficiency and profitability, but not necessarily the larger need and good of society. Classification as generic physicians fails to recognize each family physician's unique knowledge, skills, attitudes, and contributions to society.

The name primary care pbysician, another more inclusive classification, has also helped to reconnect family physicians with like-minded colleagues in internal medicine and pediatrics. This name, however, is also afflicted with troublesome features. Primary care physician defines us by a limited part of what we do, not by who we are or by our multidimensional role in society. Primary care has now been neatly caught, defined, and calculated by a national, authoritative body. ${ }^{24}$ The defining process has helped to shape crucial elements of the health care system and to suggest an agenda for education and scholarship.

The danger in defining, however, is its tendency to constrain. We now have a box called primary care, and many are starting to put things (eg, people, problems, procedures, reimbursement, etc) into that box. As a group of physicians, we are in danger of becoming defined and constrained by what is in the box. Furthermore, according to the accepted definition, primary care is not the sole province of physicians. It can be delivered by a primary care provider or a primary care clinician who need not be a physician. When family physician becomes synonymous with these broad, generic, inclusive classifications, we will have lost our cohesive group identity, a substantial measure of our professional autonomy, our sense of profes- sional self, and our good name.

Is there any way out of this onomastic conundrum? Acting on several simple suggestions may help. First, we need to be adamant about upholding and preserving the name family physician. We must faithfully teach its history and its meaning to medical students and residents. How many of them know that a Millis or a Willard report even exists? We must also aggressively educate professional colleagues, policy makers, health economists, health insurers, health system administrators, and the American public about the attributes that it embodies, and we must prove its value and benefit to society through our scholarship.

Family physician is a name that embodies many respected virtues. Society recognizes this name, values it, and regards it highly because of the solid, singularly sound reputation and trust that those who bear this name have won through their socially responsive and professional skills, attitudes, and behaviors. It is a good name that instills selfesteem, personal and professional confidence, and a strong collective identity. The contemporary American Academy of Family Physicians' definition of the family physician is clear and unambiguous. Furthermore, it encompasses the relevant attributes that were specified by the national reports that articulated society's need for this new type of physician $^{1,2}$ and that were advanced by family medicine's proponents. ${ }^{3-20}$

The family physician is a physician who is educated and trained in family practice-a broadly encompassing medical specialty.

Family physicians possess unique attitudes, skills, and knowledge which qualify them to provide continuing and comprehensive medical care, health maintenance and preventive services to each member of the family regardless of sex, age, or type of problem, be it biological, behavioral, or social. These specialists, because of their background and interactions with the family, are best qualified to serve as each patient's advocate in all health-related matters, including the appropriate use of consultants, health services, and community resources. ${ }^{25}$

Second, I suggest that we eliminate the term primary care physician from our common usage. In the context of naming physicians, primary should modify physician, not care. Family physicians belong to the larger classification of physicians that is named primary pbysicians, a descriptive term that 
was proposed by the Millis report ${ }^{1}$ and also used by McWhinney. ${ }^{6}$ The Millis report defined the primary physician as follows:

He should usually be primary in the firstcontact sense. He will serve as the primary medical resource and counselor to an individual or a family. When a patient needs hospitalization, the services of other medical specialists, or other medical or paramedical assistance, the primary physician will see that the necessary arrangements are made, giving such responsibility to others as is appropriate, and retaining his own continuing and comprehensive responsibility. ${ }^{1}$

McWhinney ${ }^{6}$ simply defined the primary physician as "a doctor who sets no horizontal limits to his field."

Stephens ${ }^{14}$ also suggested this relationship between primary physician and family physician when he stated that "the primary physician is genus and the family physician is species." Other physicians typically included with us as species in this classification system are those from general (primary?) internal medicine, general (primary?) pediatrics, and perhaps, general (primary?) obstetrics and gynecology.

The term primary physician would designate this genus of physicians as those who (1) have deep historical roots and long-established traditions that existed well before the development of branching specialties; (2) provide the principal, fundamental, essential foundation for society's system of health care; (3) are directly accessible and available to all members of society and require no intermediary to initiate or sustain health care; (4) are not derived from other medical disciplines; and (5) initiate and coordinate all patient care, including care that might require several additional steps or stages along the way. The importance of the word primary is clear when one considers that the stages following primary-secondary and tertiary-are both defined by their relationships to primary.

Third, we might want to replace the term generalist as a term for classifying physicians. Generalism is a philosophical stance or a worldview. It is one that is shared by primary physicians as well as many other physicians. Furthermore, it is not unique to medicine. Generalism also applies to most other occupations and professions. Hence it is less meaningful as a classification term specific to physicians. We should continue to emphasize its value as a way of thinking and behaving, buf limit its use as a physician name.

If we need another inclusive term to describe the family physician's practice, either compreben sivist or extensivist deserve consideration. When applied to physicians, comprehensivist would im ply that they (1) can cover a matter under consid eration completely or nearly completely; (2) can'흠 account for or comprehend all, or virtually all $\overline{\frac{\sigma}{5}}$ pertinent considerations; (3) are inclusive, and (4) have the mental power to understand or graspos widely. Extensivist would characterize them ass physicians who are widely extended in scope or application, broad in range, comprehensive, ver complete, thorough, and far-reaching. But, then, again I believe that primary physician and family? physician adequately define us.

These are difficult times for the medical profes $-\vec{V}$ sion as it struggles to survive the speed of change the stress of increasing bureaucratization and cor- poratization, and a measurable loss in its prestige and moral authority. As family physicians are in-⿳⺈⿴囗十 creasingly drawn into the fray, we need to keep our. focus sharply on who we are, what we stand for,, and where we came from. We are family physicianso -primary physicians whose knowledge, skills, and clinical practice remain the most comprehensivea and extensive of any specialty in American medi $\frac{2}{2}$ cine and who have a rich, deep, proud, and endur- $\overrightarrow{\overrightarrow{0}}$ ing heritage as physicians who specialize in caring for people. This is who I am professionally. No other name says it as well.

\section{References}

1. The graduate education of physicians: the report of the Citizens Commission on Graduate Medical Ed ucation: commissioned by the American Medical As-o sociation. Chicago, Council on Medical Education,, 0 American Medical Association, 1966.

2. Meeting the challenge of family practice: The report of the Ad Hoc Committee on Education for Family Practice of the Council on Medical Education. $\omega$ Chicago, American Medical Association, 1966.

3. Geyman JP. Family practice in evolution: progress, problems and projections. N Engl J Med 1978;298:? 593-601.

4. Geyman JP. Family medicine as an academic discipline. J Med Educ 1971;46:815-20.

5. McWhinney IR. General practice as an academico discipline. Reflections after a visit to the Unitedo States. Lancet 1966;1:419-23. 
6. McWhinney IR. The primary physician in a comprehensive health service. Further reflections after a visit to the United States. Lancet 1967;1:91-6.

7. Pisacano NJ. Generally speaking. JAMA 1970;213: 432-3.

8. Brucker PC. A chance for the generalist? J Am Board Fam Pract 1990;3(Suppl):15S-27S.

9. Spitzer WO. The intellectual worthiness of family medicine. Pharos 1977;40:2-12.

10. Stephens GG. The best ideal in family practice. J Am Board Fam Pract 1991;4:223-8.

11. Stephens GG. Fin de siecle: four modest wishes for family practice. J Am Board Fam Pract 1990;3:65-7.

12. Stephens GG. Our 20th anniversary year: remembering the Willard report. J Am Board Fam Pract 1989;2:288-90.

13. Stephens GG. Family medicine as counterculture. Fam Med 1989;21:103-9.

14. Stephens GG. The family physician and family therapy. J Fam Pract 1974;1:70.

15. Stephens GG. The intellectual basis of family practice. J Fam Pract 1975;2:423-8.

16. Stephens GG. Reform in the United States: its impact on medicine and education for family practice.J
Fam Pract 1976;3:507-12.

17. Sergent JA. Family medicine: an emergent specialty. JAMA 1967;200:106-9.

18. Carmichael LP. The family in medicine, process or entity? J Fam Pract 1976;3:562-3.

19. Carmichael LP. A different way of doctoring. Fam Med 1985;17:4.

20. Carmichael LP. Psychiatry and family medicine. New Physician 1970;19:525-7.

21. Hayakawa SI. Classification. In: Language in thought and action, 3rd ed. New York: Harcourt Brace Jovanovich, 1972.

22. Shakespeare W. Othello. New York: EP Dutton \& Co, 1934.

23. McWhinney IR. Family medicine as a science. J Fam Pract 1978;7:53-8.

24. Donaldson MS, Yordy KD, Vanselow NA, editors, Institute of Medicine, Division of Health Care Services, Committee on the Future of Primary Care. Defining primary care: an interim report. Washington, DC: National Academy Press, 1994.

25. American Academy of Family Physicians. Family physician: definition. http://www.aafp.org/policy/46. html\#1. 1993. 